\title{
CICLISMO DE VELOCIDADE: MEIOS DE TREINAMENTO DE FORÇA
}

Fernando Ruiz Fermino

Paulo Roberto de Oliveira

\section{Resumo}

A força constitui um fator importante em qualquer atividade desportiva, sendo determinante em alguns casos e se desenvolvida de uma maneira correta, nunca será prejudicial ao atleta (Badilo, 2001). Uma das características do desenvolvimento da força é satisfazer as necessidades específicas do desporto (Bompa, 2004), portanto o treinamento busca cada vez mais, meios especializados e de maior potencial de estímulos. Sendo o ciclismo uma modalidade composta por diferentes provas, onde a predominância de treinamentos voltados para o desenvolvimento da capacidade de resistência ainda estão amplamente difundidos; o presente estudo procura ressaltar a importância de classificar os meios de treinamento de acordo com seu potencial de estimulo, nas provas de velocidade no ciclismo.

\section{Palavras-Chave}

Ciclismo; Meios de Treinamento; Força.

\section{SPEED CYCLING: MEANS OF STRENGTH TRAINING}

Fernando Ruiz Fermino

Paulo Roberto de Oliveira

\begin{abstract}
The strength constitutes a very important factor in any sporting activity, being determinant in some cases and if it is developed in a correct way, it will never be harmful to the athlete (Badilo, 2001). One of the characteristics of the strength development is satisfy the specific sports needs (Bompa, 2004), therefore the training aims more specialized means and with the biggest stimulus potential. Cycling is a modality that consist of different events, where the predominance of training directed to the resistance capacity development still are amplely disseminate, the present studies search rebound the importance of classifying the training means according to the stimulus potential, in the cycling speed events.
\end{abstract}

\section{Key-Words}

Cycling; Means training; Strength. 


\section{INTRODUÇÃO}

A atenção manifestada ao desenvolvimento do desporto se deve a sua crescente popularidade, e como conseqüência tem-se entre outros aspectos o aumento dos números de competições, melhoria da organização e evolução dos sistemas de preparação do atleta. Isso tem permitido a renovação constante dos recordes mundiais, exigindo que especialistas do desporto busquem maneiras de aperfeiçoar o sistema de preparação desportiva. Em países de expressividade desportiva a pratica da preparação dos atletas associada às investigações sobre teoria e metodologia do treinamento, caracterizam as principais tendências que têm condicionado o progresso do desporto mundial. A evolução na organização da preparação desportiva deve-se entre outros fatores, a sua correção baseada em estudos e controle tanto da tendência geral de desenvolvimento como das particularidades de cada desporto. (PLATONOV, 2004).

O desenvolvimento de uma atividade desportiva representa a utilização orientada dos complexos fatores que envolvem a preparação do desportista, destacando-se: sistema de competição, representado por competições oficiais e não oficiais que por si só não garante a preparação plena do desportista; sistema de treinos, constituintes do componente central da preparação desportiva, representado por um processo pedagogicamente organizado, cuja base é constituída pelos métodos de exercícios físicos que visam desenvolver as potencialidades máximas do organismo; e sistema de fatores complementares, como a fisioterapia, massagens, alimentação, meios farmacológicos, entre outros. (ZAKHAROV, 2003).

A base metodológica da preparação desportiva é constituída por exercícios físicos, que integrado ao processo de preparação pode ser definido como "a ação motora inclusa no sistema geral das possíveis influências pedagógicas e orientadas para a solução de tarefas da preparação do atleta", que na linguagem desportiva também conhecida por meio de treinamento. (ZAKHAROV, 2003).

De acordo com Siff e Verkhoshansky (2004), as formas de treinamento de força são diferentes e produzem efeitos significativamente diferentes, portanto na seleção dos exercícios deve-se levar em consideração a forma de execução, pois é de vital importância recordar que todo exercício envolve estímulos que são processados no sistema nervoso central e periférico, devendo considerar principalmente o tipo de contração, velocidade e o padrão de movimento. "O aperfeiçoamento físico do indivíduo adquire uma orientação especial de preparação somente quando os exercícios são selecionados, levando em consideração seu significado para o aperfeiçoamento da ação motora na modalidade desportiva escolhida". 
[...] É por isso que se utiliza mais amplamente, na teoria e na prática de preparação dos atletas, a classificação dos exercícios físicos segundo o indício da medida de semelhança das características cinemática e dinâmica das ações motoras que compõem o exercício físico dado, com as ações motoras que baseiam a modalidade escolhida da atividade competitiva. De acordo com este indício, todos os exercícios físicos dividem-se em exercício competitivo, preparatório especial e preparatório geral" (ZAKHAROV, 2003).

Platonov e Bulatova (2003), apresentam as seguintes classificações e definições para os exercícios de treinamento e competição:

1. Exercícios de preparação geral - servem para o desenvolvimento funcional do organismo do desportista, podem corresponder a particularidades de uma modalidade esportiva, assim como podem ser contrários até certo ponto. A preparação geral visa desenvolver as qualidades motoras, indispensável para o aperfeiçoamento de uma determinada modalidade. No ciclismo podemos selecionar exercícios realizados com pesos, desde que solicitem os músculos utilizados no movimento de pedalar.

2. Exercícios de preparação especial - ocupam um lugar primordial no sistema de preparação física de atletas de alto nível e abrangem um conjunto de meios que inclui elementos da atividade competitiva, com ações muito similares a esta atividade, seja em sua forma, sua estrutura, no caráter das qualidades intervenientes e/ou das atividades dos sistemas funcionais do organismo, criando uma base especial para o volume de trabalho destinado as capacidades motoras específicas, escolhendo exercícios que possuem características dinâmicas e cinemáticas correspondente. No ciclismo podemos selecionar exercícios em cicloergômetro, esforços em subidas, saltos, entre outros.

3. Exercícios de competição - pressupõem a execução de um conjunto de ações motoras que constituam o objetivo da especialização esportiva, sempre seguindo as regras existentes na competição.

O ciclismo é composto por provas de estrada e velódromo que por sua vez, são divididas em provas de meio fundo e de velocidade. Consequentemente as exigência motoras e metabólicas são diferentes para cada prova, o que evidência a importância do estudo particular de cada modalidade, respeitando assim um dos princípios do treinamento desportivo, a especificidade da carga de treinamento, a qual por sua vez deve ir de encontro com as exigências do exercício competitivo. Segundo Paltonov (2003), é 
indispensável um enfoque diferenciado da preparação para cada grupo de desporto.

No mundo e no Brasil o ciclismo de velódromo, em especial as provas de velocidade não são amplamente difundidas como as provas de estrada, o que torna ainda mais difícil as conclusões acerca do sistema de preparação.

\section{CONSIDERAÇÕES PARA ORGANIZAÇÃO DO SISTEMA DE TREINAMENTO NO CICLISMO}

Para o desenvolvimento do sistema de preparação do ciclista especializado em provas de velocidade, devem ser identificados os músculos envolvidos na ação de pedalar, classificação dos exercícios de treinamento de acordo com a especificidade e orientação metabólica da atividade a ser desenvolvida, modelo de treinamento a ser empregado, com o objetivo de reunir parâmetros confiáveis que norteiem a estruturação do treinamento do desportista.

\section{PRINCIPAIS MÚSCULOS ENVOLVIDOS NA PEDALADA}

A pedalada é composta basicamente de duas fases:

- Descendente, com deslocamento do pedal do ponto superior até o inferior, solicitando principalmente os seguintes músculos: glúteo máximo e médio, quadríceps (vastos laterais, intermédio, medial e reto femoral), gastrocnêmio e sóleo; essa é a fase em que ocorre o maior desenvolvimento da potência.

- Ascendente, o pedal desloca-se da parte inferior para a superior; os principais músculos solicitados neste movimento são: reto femoral, ílio psoas, ísquio tibiais (bíceps femoral, semitendinoso e semimembranoso) e tibial anterior (BAILLY, 1998; RAYMOND, 2005).

\section{ATIVAÇÃO DOS MÚSCULOS DURANTE O CICLISMO}

Os modelos de ativação do músculo fornecem informações sobre como o sistema nervoso central controla o movimento.

A seguir são apresentados os modelos médios de ativação de 10 músculos de membros inferiores durante 15 ciclos de pedalada em 18 ciclistas experientes, pedalando com 90 rotações por minuto (rpm) e 250 watts $(\mathrm{w})$. 
A curv:

(superiı

Atravé:

nas dist

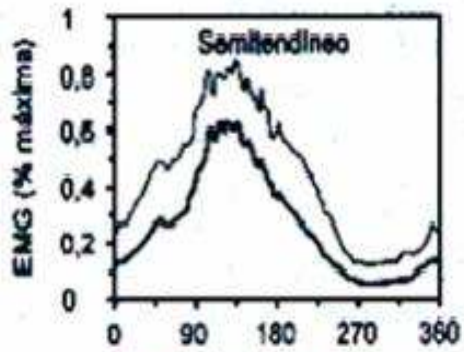

Angulo do po de vela (orrus)



Angulo do po do velo (oraus)
ARTIGO

curva mais clara

-ica dos músculos

FIGURA 1 - Modelo médio de ativação de músculos durante o ciclo de pedalada.

(Garrett e col., 2003)

OBS: O ponto superior do movimento de pedalar ("doze horas no relógio"), representa zero grau na figura abaixo.


FIGURA 1 - Modelo médio de ativação de músculos durante o ciclo de pedalada.

(Garrett e col., 2003)

Fonte: Garret et al., 2003

\section{Exercícios Gerais no Ciclismo}


$\mathrm{Na}$ atual concepção do treinamento do ciclista de alto desempenho, os exercícios gerais devem envolver os músculos solicitados no gesto de pedalar, ainda que não contemplem integralmente o movimento da pedalada ou, o metabolismo específico. A seguir são apresentados alguns exercícios realizados com pesos, para o desenvolvimento capacidade biomotora de força no ciclismo, alguns comumente encontrados na literatura especializada e outros incorporados de acordo com a necessidade de priorizar os grupos musculares específicos; isso significa que além desses, outros podem ser criados de acordo com a disponibilidade dos meios, desde que tenha relação com os grupos musculares solicitados na atividade competitiva, considerando que o tipo de contração muscular envolvida na pedalada é dinâmica concêntrica e o padrão de movimento é cíclico.

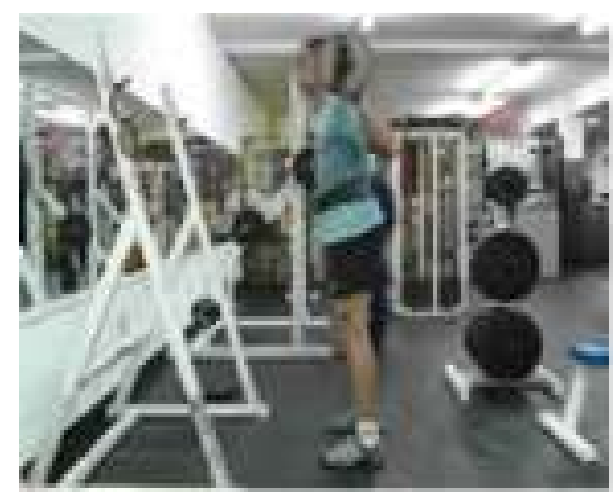

Figura 2 - Agachamento posição inicial

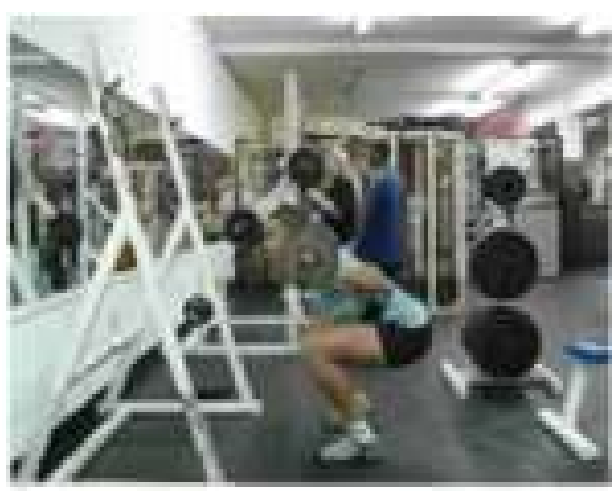

Figura 3 - Agachamento posição final

Solicitação dos músculos utilizados na fase descendente: Glúteo Máximo e Médio, Quadríceps, Bíceps femoral, Gastrocnêmio e Sóleo.

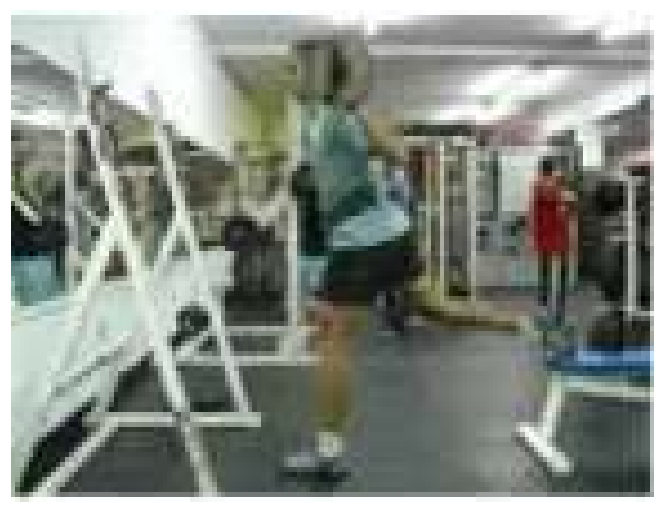

Figura 4 - Agachamento com 1 perna posição inicial



Figura 5 - Agachamento com 1 perna posição final

Solicitação dos músculos utilizados na fase descendente: Glúteo Máximo e Médio, Quadríceps, Bíceps femoral, Gastrocnêmio e Sóleo. 




Figura 6 - Afundo posição inicial

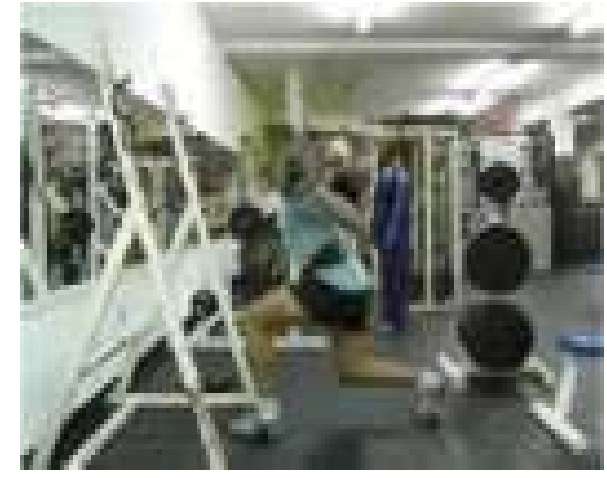

Figura 7 - Afundo posição final

Solicitação dos músculos utilizados na fase descendente: Glúteo Máximo e Médio, Quadríceps, Bíceps femoral, Gastrocnêmio e Sóleo

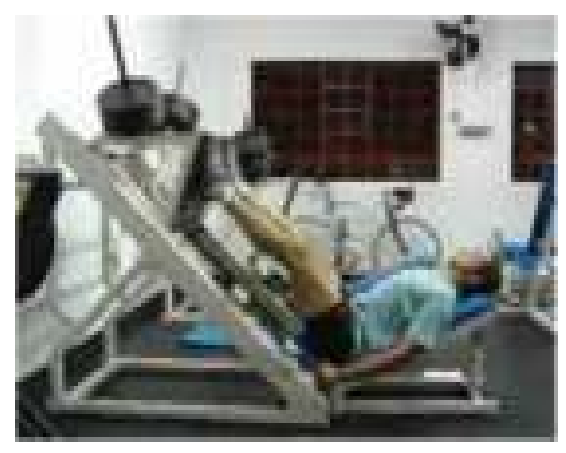

Figura 8- Leg press posição inicial

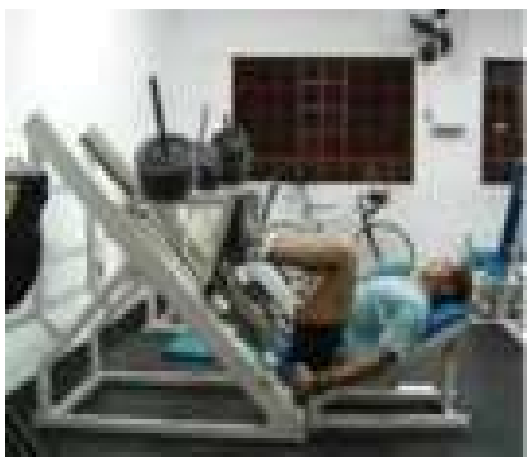

Figura 9 - Leg Press Posição Final

Solicitação dos músculos utilizados na fase descendente: Glúteo Máximo e Médio, Quadríceps, Bíceps femoral, Gastrocnêmio e Sóleo.

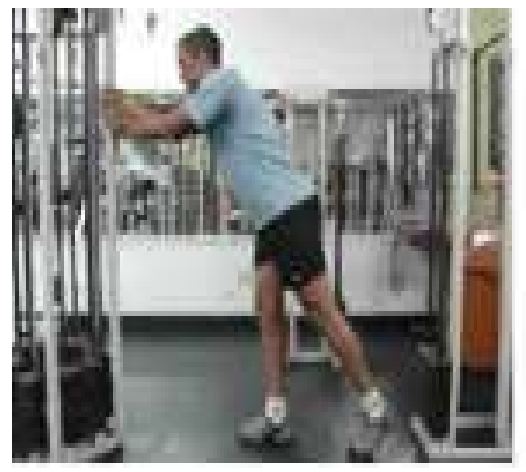

Figura 10 - Flexão de quadril posição inicial

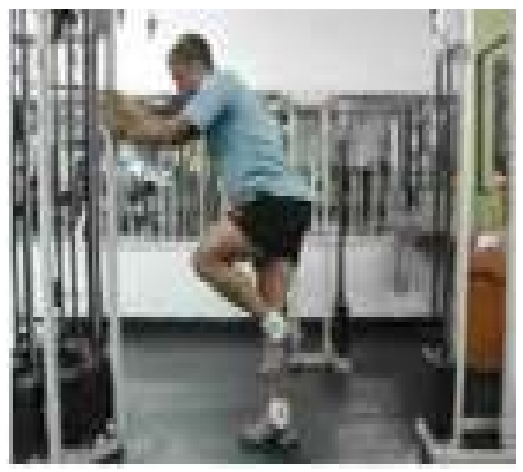

Figura 11 - Flexão de quadril posição final

Solicitação dos músculos utilizados na fase ascendente: reto femoral, ílio psoas, isquiotibiais e tibial anterior. 


\section{EXERCÍCIOS ESPECIAIS NO CICLISMO}

Os exercícios de preparação especial de força possuem características mais próximas da atividade competitiva, podendo ser desenvolvidos em bicicletas de competição ou similares e em ciclo ergômetros, respeitando assim as características da pedalada e aproximando do metabolismo específico, no entanto, para o incremento da componente de força devem ser realizados com carga adicional. Os exercícios de saltos, de acordo com a literatura especializada classificam-se como especial devido ao tipo de contração e considerando que no ciclismo a contração muscular é concêntrica dinâmica, justifica-se sua utilização como exercício especial. A seguir são apresentados alguns exercícios que podem ser utilizados para preparação especial de força; devem ser adotados e ou criados de acordo com sua disponibilidade e acessibilidade.

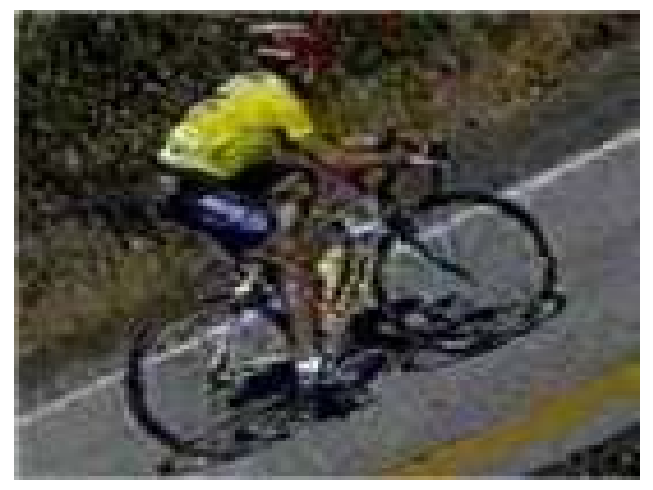

Figura 12 - esforços na subida

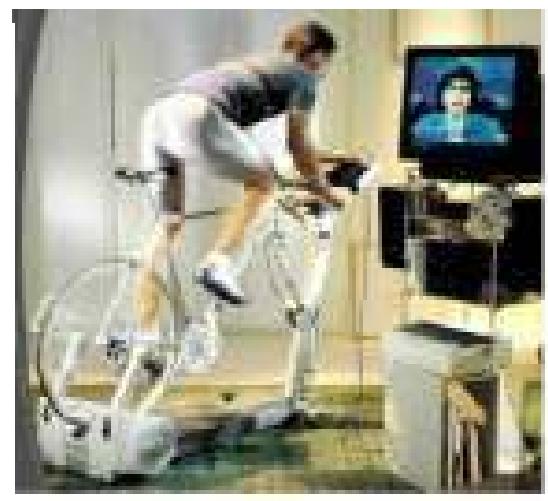

Figura 14 - Esforço no Ciclossimulador

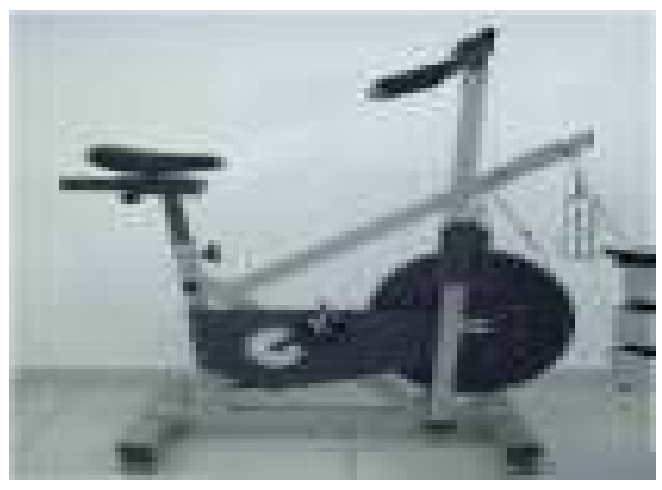

Figura 13 - Esforços no cicloergômetro

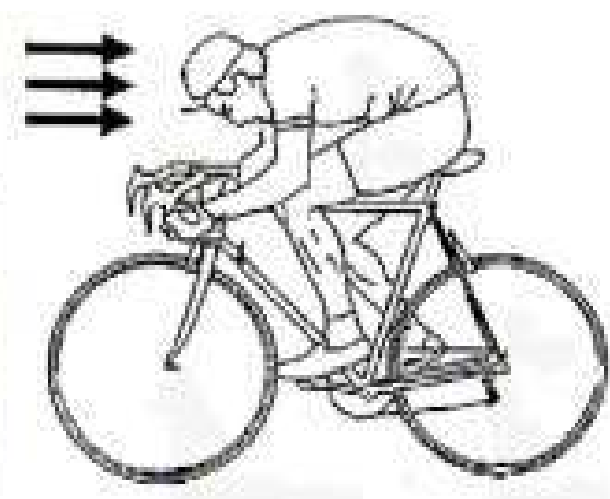

Figura 15 - Esforços contra o vento 

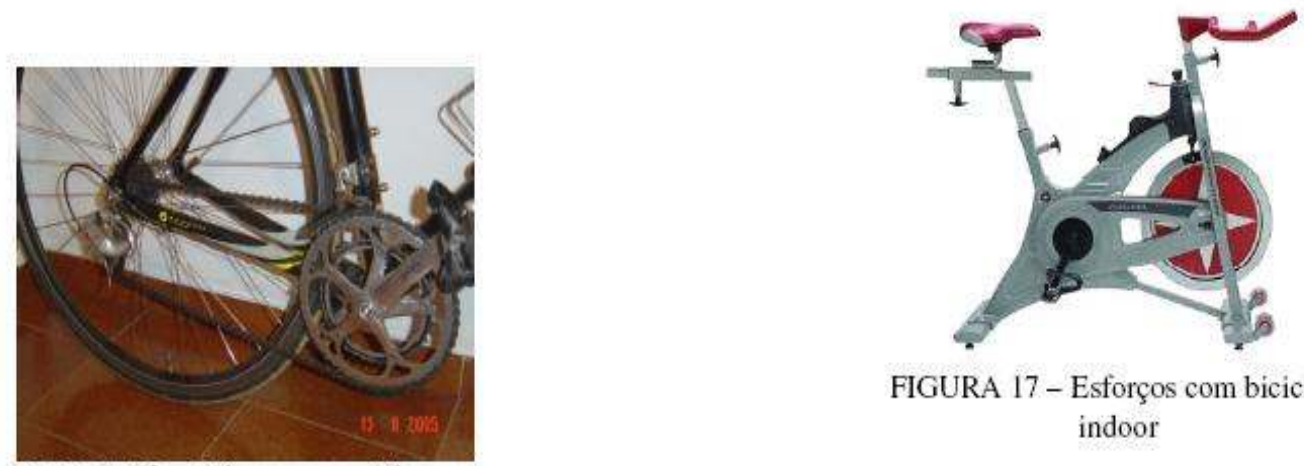

FIGURA 17 - Esforços com bicicleta indoor

FIGURA 16 - Esforços com diferentes transmissões

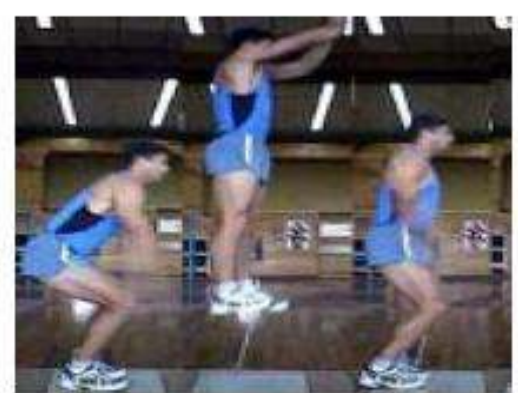

FIGURA 18- Exercícios de salto

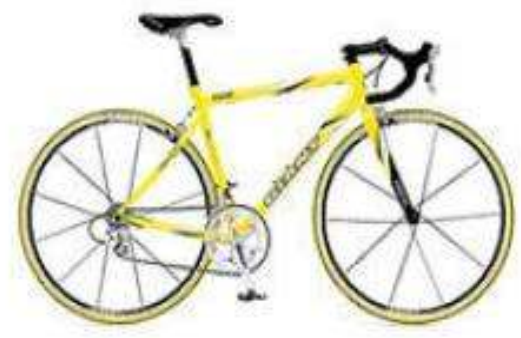

FIGURA 19 - Exercícios com bicicleta de estrada

\section{CLASSIFICAÇÃO DO RELEVO}

Diversas são as formas de aumentar a resistência externa, uma maneira interessante de intensificar o exercício no ciclismo é realizá-lo em diferentes condições de relevo, portanto apresentaremos um sistema de classificação objetiva da topografia segundo a inclinação a fim de contemplar diferentes solicitações da capacidade biomotora de força. Uma grande porcentagem de inclinação objetiva o uma maior solicitação da força propriamente dita e uma menor porcentagem de inclinação está relacionada com a resistência de força.

\section{QUADRO 1 - Utilizado para orientação da topografia segundo a inclinação}

\begin{tabular}{lll}
\hline Código & Denominação & Descrição \\
\hline S I & Subida Um & Subida com pequena inclinação ou falso plano \\
S II & Subida Dois & Subida com moderado grau de inclinação \\
S III & Subida Três & Subida com elevado grau de inclinação \\
p & Plano & $\begin{array}{l}\text { Superfície isenta de qualquer inclinação, inclui também } \\
\text { velódromos }\end{array}$ \\
\hline
\end{tabular}

Conexões, revista da Faculdade de Educação Física da UNICAMP, Campinas, v. 6, ed. especial, p. 22-34, jul. 2008. ISSN: $1983-9030$. 


\section{ORIENTAÇÃO DA CADÊNCIA DE PEDALADA}

Uma variável que se deve levar em consideração na elaboração do plano de treinamento para o ciclismo é a cadência (freqüência de pedalada) medida em rotações por minutos (rpm), as quais foram determinadas a partir de porcentagens da máxima cadência atingida em competição.

Para o desenvolvimento da capacidade biomotora de força e resistência de força sugerimos cadências abaixo de setenta por cento da máxima, onde são realizadas sobre influências de grandes resistências externas.

\section{QUADRO 2 - orientação da cadência}

\begin{tabular}{cc}
\hline \% MÁXIMA & OBJETIVO \\
\hline $40-50$ & Força de Resistência (FR) \\
$51-60$ & Resistência Força I (RF I) \\
$61-70$ & Resistência Força II (RF II) \\
\hline
\end{tabular}

\section{DETERMINAÇÃO DAS TRANSMISSÕES}

Transmissão é a relação de marchas formada entre as engrenagens das coroas e pinhões, a qual deve ser levada em consideração na aplicação do treinamento. Devemos nos ater a distância percorrida por um ciclo de pedalada, representado na quarta coluna do quadro abaixo, quanto maior for esta, mais componentes da capacidade biomotora de força estarão sendo solicitados. 


\section{QUADRO 3 - classificação das transmissões}

\begin{tabular}{ccccc}
\hline Código & $\begin{array}{l}\mathrm{N}^{\circ} \text { de dentes } \\
\text { da coroa }\end{array}$ & $\begin{array}{l}\mathrm{N}^{\circ} \text { de dentes } \\
\text { do pinhão }\end{array}$ & Distância $(\mathrm{m})$ & $\begin{array}{l}\mathrm{N}^{\circ} \text { Pedalada } \\
\text { por km }\end{array}$ \\
\hline $52 \times 16$ & 52 & 16 & 7.00 & 142.9 \\
$52 \times 15$ & 52 & 15 & 7.46 & 134.0 \\
$52 \times 14$ & 52 & 14 & 8.00 & 125.0 \\
$51 \times 16$ & 51 & 16 & 6.86 & 145.7 \\
$51 \times 15$ & 51 & 15 & 7.32 & 136.6 \\
$51 \times 14$ & 51 & 14 & 7.84 & 127.5 \\
$50 \times 16$ & 50 & 16 & 6.73 & 148.6 \\
$50 \times 15$ & 50 & 15 & 7.18 & 139.3 \\
$50 \times 14$ & 50 & 14 & 7.69 & 130.1 \\
$49 \times 16$ & 49 & 16 & 6.59 & 151.7 \\
$49 \times 15$ & 49 & 15 & 7.03 & 142.2 \\
$49 \times 14$ & 49 & 14 & 7.54 & 132.7 \\
$48 \times 16$ & 48 & 16 & 6.46 & 154.8 \\
$48 \times 15$ & 48 & 15 & 6.89 & 145.1 \\
$48 \times 14$ & 48 & 14 & 7.38 & 135.5 \\
\hline
\end{tabular}

\section{Orientação do Treinamento de Força Especial}

Para orientação objetiva do processo de treinamento das distintas manifestações de força especial do ciclista (força de resistência e resistência de força), importantes no processo de aperfeiçoamento da velocidade de deslocamento nas provas de velocidade no ciclismo, apresentaremos zonas de treinamento com os respectivos parâmetros orientadores do exercício.

QUADRO 4 - Parâmetros de orientação do treinamento de força especial do ciclista FRF.

\begin{tabular}{|c|c|c|c|c|c|c|}
\hline Sigla & Trajeto & Relacao & Duracao & Distância (m) & Partida & $\begin{array}{c}\text { Cadência } \\
\text { (rpm) }\end{array}$ \\
\hline FR & SIII & $52 \times 14 / 15 / 16$ & Até 20s & Até 150 & Parada/lançada & $50-60$ \\
\hline RFI & SII & $53 \times 14 / 15 / 16$ & 45 a $70 s$ & $400-600$ & lançada & $61-80$ \\
\hline RFII & SI & $52 \times 14 / 15 / 16$ & 50 a $110 \mathrm{~s}$ & $500-1000$ & lançada & $81-100$ \\
\hline
\end{tabular}

\section{CONSIDERAÇÕES FINAIS}

Tratando-se do ciclismo de velocidade, o aprimoramento da força torna-se importante, pois de acordo com Verkhoshansky (2001), a capacidade de força desempenha grande papel na gestão da velocidade. No entanto suas características de manifestação são diferentes e influenciadas pelos meios de treinamento 
aplicados, os quais de acordo com Zakharov (2003), são representados pelos exercícios físicos e constituem a base da preparação do atleta.

A preparação física do desportista depende entre outros fatores, da habilidade de selecionar os meios de preparação e do conhecimento de seu potencial de estímulo, o que permitirá o desenvolvimento de um sistema de treinamento objetivo para o estabelecimento de um programa de preparação geral e especial no ciclismo de velocidade.

\section{REFERÊNCIAS}

BADILlO, J. J. G.; AYESTARÁN, E.G. Fundamentos do treinamento de força: aplicação ao alto rendimento desportivo. 2. ed. Porto Alegre: Artmed, 2001.

BAILLY, L. Manual del curso de entrenadores solidaridad olímpica: UCI, 1998.

BOMPA, T. O. Treinamento de potência para o esporte. São Paulo: Phorte, 2004.

BURKE, E. R. Science of cycling. Human Kinetics Books, 1986.

DELAVIER, F. Guia dos movimentos de musculação. 2. ed. São Paulo: Manole, 2000.

FRIEL, J. The cyclists's training bible 2. ed. Colorado: Velo Press, 1996.

GARRET, William E.; KIRKENDALL, Donald T. A ciência do exercício e dos esportes. Porto Alegre, Artmed, 2003.

GARRET, W. E.; KIRKENDALL, D. T. A ciência do exercício e dos esportes. Porto Alegre: Artmed, 2003.

PlATONOV, V. N.; BULATOVA, M. N. A preparação física. Rio de Janeiro: Sprint, 2003.

RAYMOND, C.H.; JOSEPH, K.F.; GABRIEL, Y. F. Muscle recruitiment pattern in cycling: a review. Physical Therapy in Sport. v. 6, n. 2, p. 89-96, feb. 2005.

SCHMITZ, E.; DOYLE, K. Weight training for cyclists. Colorado, Velo, 1998.

SIFF, M.; VERKHOSHASKY, Y. V. Superentrenamiento. 2. ed. Barcelona: Paidotribo, 2004.

VERKHOSHASKY, Y. V.; OLIVEIRA, P. R. Preparação de força especial. Rio de Janeiro: Grupo Palestra Sport, 1995.

ZAKHAROV, A. A. GOMES, A. C. Ciência do treinamento desportivo. 2. ed. Rio de Janeiro: Grupo Palestra Sport, 2003.

ZATSIORSKY, V. M. Ciência e prática do treinamento de força. São Paulo: Phorte, 1999 


\section{Fernando Ruiz Fermino}

\section{Faculdade de Educação Física- UNICAMP}

\section{Paulo Roberto de Oliveira}

Faculdade de Educação Física / UNICAMP

\section{Referência do artigo:}

\section{ABNT}

FERMINO, F. R.; OLIVEIRA, P. R. Ciclismo de velocidade: meios de treinamento de força. Conexões, v. 6, ed especial, p. 22- , 2008.

\section{APA}

Fermino, F. R., OLIVEIRA, P. R. (2008). Ciclismo de velocidade: meios de treinamento de força. Conexões, v. 6, (ed. especial), 22-34.

\section{VANCOUVER}

Fermino FR., OLIVEIRA PR. (2008). Ciclismo de velocidade: meios de treinamento de força. Conexões, v. 6, (ed. especial): 22-34. 